\title{
El arte del Perú Antiguo visto por los viajeros del siglo XIX: Wiener, Squier y Marcoy*
}

\author{
Virgilio Freddy Cabanillas**
}

Resumen En este artículo presentamos las opiniones de tres viajeros del siglo XIX: el francés Marcoy, el norteamericano Squier y el austriaco Wiener. Todos ellos jugaron un papel importante en el proceso de descubrimiento y revaloración del arte andino autónomo. En sus libros describieron detenidamente obras de arte de diversas técnicas, culturas y períodos; reprodujeron sus imágenes e hicieron audaces interpretaciones que ejercieron notable influencia por la difusión que alcanzaron sus escritos.

Marcoy estaba convencido del origen foráneo de nuestras culturas. Squier en cambio, defendía la originalidad del arte andino y elogió sus diversas manifestaciones. Por su parte Wiener, aplicó criterios clásicos para criticar la representación escultórica humana, pero resaltó los valores de la arquitectura.

Palabrasclave: Perú Antiguo, arte andino, viajeros, siglo XIX.

Abstract In this article we discuss the statements of three XIX century travelers: Paul Marcoy, Efrain G. Squier, and Charles Wiener, these travelers played a significant role in the process of discovery and revaluation of the autonomous Andean art. In their books, they described in detail artistic objects of several techniques, cultures, and periods. They also made high quality drawings of these objects and proposed audacious inter-pretations that had a significant influence due to the diffusion of their manuscripts. Marcoy was conuinced of the foreign origin of Andean cultures. In contrast, Squier advocated for the singularity of Andean art and eulogized its diferent manifestations. Meanwhile, Wiener criticized the patterns of human sculpture in the Andes under classic criteria, but remarked the quality of arquitectural buildings.

Keywords $=\quad$ Ancient Peru, Andean art, travelers, XIX century.

\footnotetext{
* Este artículo surgió a partir de una conferencia que dimos en el Museo de Arqueología y Antropología de la UNMSM, dentro del programa de los Miércoles Arqueológicos y Antropológicos (22-10-03).

** Profesor de la Universidad Nacional Mayor de San Marcos.
} 
"He sido feliz en el Perú... iHe realizado excavaciones! He sacado con qué llenar una media sala del Louvre."

(Carta de Charles Wiener, 11-03-1876)

El arte de la Civilización Andina alcanzó niveles de exquisitez y complejidad que los peruanos hemos descubierto y valorado tardíamente. Es interesante recorrer este proceso de revaloración que tiene antecedentes a mediados del siglo XIX (Antigüedades peruanas de Tschudi y M. E. de Rivero, Francisco Laso, los viajeros), pasa por los descubrimientos y teorizaciones de Uhle y Tello, y llega a la obra de artistas como Elena Izcue, Manuel Piqueras, Francisco Gonzáles Gamarra y otros, que utilizan los íconos del Antiguo Perú en su quehacer artístico. En este artículo revisaremos algunas páginas de esta historia, las opiniones de tres exploradores extranjeros: el francés Marcoy, el norteamericano Squier y el austriaco Wiener.

\section{Paul Marcoy, seudónimo de Laurent Saint-}

Cricq (1815-1888): Viaje a través de América del Sur. Del Océano Pacífico al Océano Atlántico. ${ }^{1}$

Este viajero autodidacta e independiente recorrió el Perú en los años 40 del siglo XIX y publicó su libro en París, en dos tomos, con 626 ilustraciones y 20 mapas (1869). Las "vistas, retratos y paisajes" fueron obra de E. Riou.

Marcoy estaba convencido del origen foráneo de las culturas americanas. Primero se hizo presente el elemento "colonizador" asiático y luego el elemento "civilizador" egipcio. La alta cultura se habría afincado inicialmente en México y posteriormente en los Andes. La cultura se difundió desde el norte hacia el sur "empobreciéndose" progresivamente (Chaumiel, 2001: 27).

Estos presupuestos están presentes constantemente cuando analiza los monumentos y objetos andinos. Por ejemplo, cuando se refiere a las chullpas, considera que su forma "... recordabapor su configuración general, los teocallis mexicanos, cuyo modeloparece haber sido tomado en préstamo al templo de Bel" (2001: 138). La influencia china también está presente, en este caso en la arquitectura de pucaras y andenes (2001: 298). Los objetos de oro y plata le causan buena impresión y los considera "... de un estilo que recuerda Etruria y Egipto” (2001:316).

El arte textil despertó tempranamente la curiosidad y admiración de los viajeros. Marcoy describe con acierto y minuciosidad una manta decorada con diseños geométricos y naturalistas: "Era de algodón blanco y bastante gruesa, y atravesadapor rayas de tres dedos de ancho, colocadas a medio pie de distancia unas de otras. En ellas se cruzaban y combinaban, según el logaritmo de la más caprichosa fantasía, grecas, meandros, entrelazados, dameros, cruces, billetes, estrellas, mezcladas con caracteres jeroglíficos y figuras de hombres y mujeres, de cuadrúpedos y pájaros. Todo ello pintado con colores un poco apagados, se asemejaba, a tres pasos de distancia, a un tejido de Cachemira" (2001:315). ${ }^{2}$

Sobre la cerámica andina, Marcoy afirmó que sus mejores logros se obtuvieron durante el gobierno de Pachacútec, considerando que su exitosa administración propició un desarrollo de las

\footnotetext{
${ }^{1}$ Hemos consultado la edición en español del 2001 (ver bibliografía).

${ }^{2}$ Pocos años después de la publicación del libro de Marcoy se realizan las excavaciones arqueológicas de Ancón a cargo de los alemanes Reiss y Stübel (1875). Hoy se considera que éste fue el trabajo pionero de la arqueología de campo con método en el Perú. Fue además un trabajo multidisciplinario. El resultado fue el libro: La Necrópolis de Ancón en Perú. Una contribución al conocimiento de la cultura y la industria del reino inca según los resultados de las excavaciones de W. Reiss y A. Stübel. La obra está magníficamente ilustrada con 141 litografías a color. Una carta de Stübel contiene observaciones sobre los logros artísticos de la textilería andina: “... de hecho debe sorprender, cuando se contemplan los tejidos cuya ejecución es tan perfecta que pueden compararse con algunos de nuestros más finos gobelinos . Las figuras
} 


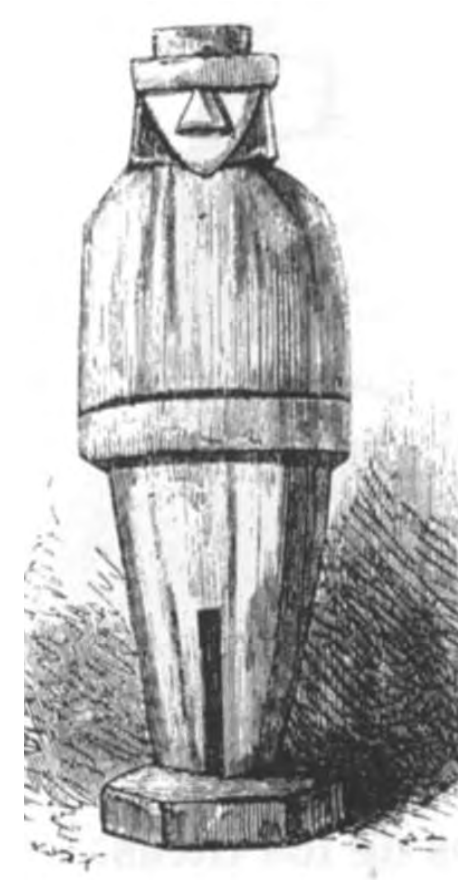

"Estatuilla de basalto de tiempo de los incas". Marcoy.

Compárese el estilo con las siguientes ilustraciones.

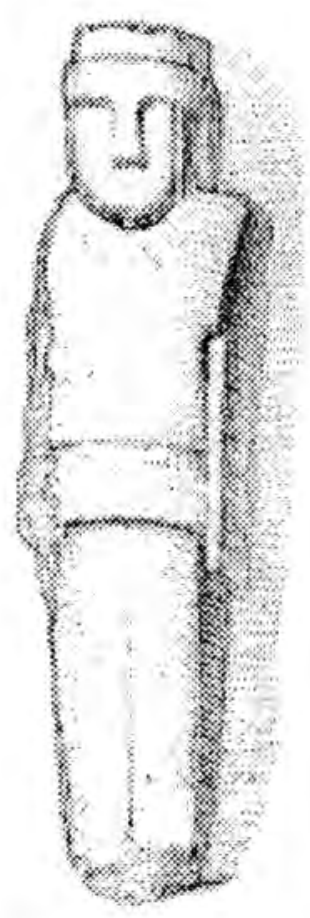

Escultura Pukara. Dibujo de Juan Jacobo Tschudi.

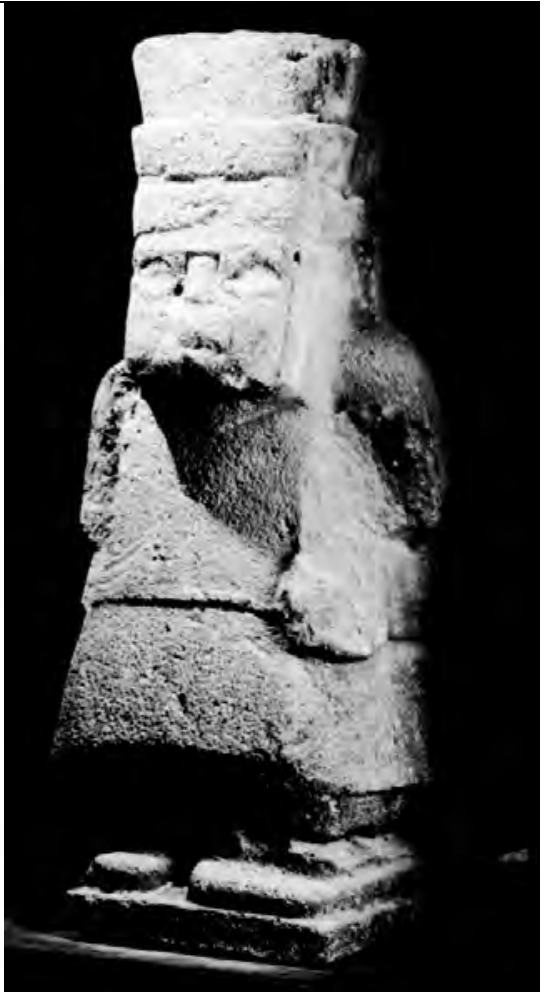

Monolito antropomorfo. Cultura Wari (Kauffmann, 2002: 383). artes: "Fue durante el reinado de Pachacútec que el arte de la cerámica alcanzó toda su perfección. Los vasos de una pasta tan fina, de un galbo tan puro y de una originalidad tan clara, que admiramos hoy día" (2001:315).

\section{Efraim George Squier (1821-1888): Unviaje} por tierras incaicas. Crónica de una expedición arqueológica. 1863-1865. ${ }^{3}$

Este libro se publicó originalmente en 1877 en la ciudad de Nueva York, con el título Perú: incidents of travel and exploration in the land of the incas. El voluminoso texto fue acompañado por un repertorio de cuatrocientas ilustraciones. La pági- na titular luce como viñeta un escudo con serpiente, sol, arco iris, ave bicéfala y torres almenadas.

Squier llegó al Perú en misión diplomática y realizó sus exploraciones con un itinerario similar al de Cieza de León. Raúl Porras Barrenechea lo considera "el gran pionero de la arqueología científica" en el siglo XIX; "superando el empirismo romántico y descriptivo de los anteriores viajeros". (Porras, 1963: 62-64).

A diferencia de Marcoy, Squier defiende el carácter autónomo de nuestras culturas ancestrales: "...no hay pruebas válidas de que los progenitores de los peruanos, dentro de cualquier período

tejidas corresponden muy de cerca al estilo etrusco, mientras los colores frecuentemente están bien conservados como si la lana hubiera sido teñida ayer y no hace unos 600 y hasta 1000 años" (Carlson, 2000: 9). El tejido andino es evaluado positivamente, pero -al igual que en la obra de Marcoy- todavía es inevitable la referencia al arte del Viejo Mundo.

${ }^{3}$ Hemos consultado la edición en español de 1974 (ver bibliografía). 
país desde el exterior o que su civilización les fuera impartida por cualquier otra raza" (1974:311). Al observar la arquitectura inca, señala que por su carácter macizo, inclinación de paredes y estilo de cornisas se parece a Egipto. Sin embargo -afirma- esta similitud no significa necesariamente una conexión real (1974 : 235).

Una de sus observaciones más penetrantes y de angustiante actualidad, fue la despiadada práctica del saqueo de los tesoros arqueológicos: "Tal vez nuestra visita dio nuevo impulso a la excavación de dinero o búsqueda de tesoros que, si me llamaran a declarar, diría que es la principal ocupación de la gente en el Perú. El tiempo, trabajo y dinero que se han empleado en excavar y desmantelar antiguos edificios, hubieran construido un ferrocarril de un extremo a otro del país, dado muelles a los puertos y, lo que es mucho más importante, cloacas a las ciudades" (1974 : 261). En su viaje al norte busca el apoyo de un tal Cnel. La Rosa para llegar a los monumentos que se ha propuesto estudiar. Se trataba de un conocido buscador de tesoros que no pudo ocultar su desconfianza en el viajero "... no simpatizó mayormente con mis planes de reconocimiento, medición y confección de planos de los monumentos y evidentemente pensó que mi declaración de tales propósitos era tan sólo un pretexto frívolo para distraer la atención de mi objetivo real, el de encontrar el peje grande o 'pez grande', nombre con que se ha designado desde tiempo inmemorial el legendario tesoro, aún no descubierto, de los chimús, y en cuya búsqueda se han gastado millones de dólares" (1974:62). Las "hazañas" de este personaje impactaron a Squier: "El coronel La Rosa afirmó que había encontrado aquí algunas vasijas de oro, que vendió por peso para su exportación en forma de lingotes. Es probable que siempre constituya una fuente de pesar para los anticuarios el hecho de que estos objetos, infinitamente más valiosos desde un punto de vista artístico y científico que desde cualquier otro, no hayan caído en manos más ilustradas" (1974 : 76).

Si duda alguna, el libro de Squier es fundamental en este proceso de descubrimiento del arte del Antiguo Perú y por eso merece ser resaltado de manera especial. Las comparaciones con el

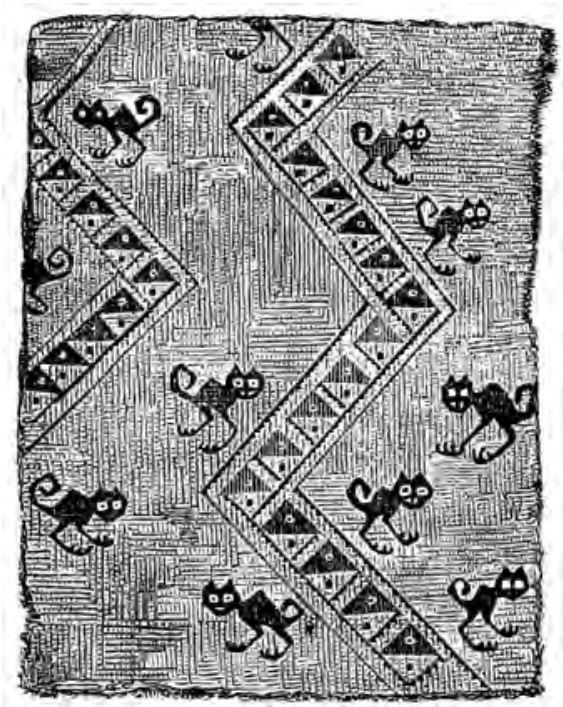

Textil de Pachacamac. "Modelo de mortaja de algodón". Squier.

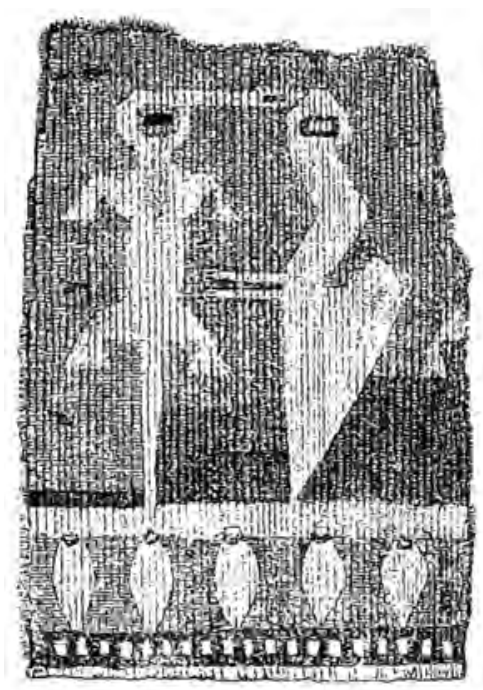

"Muestra de tela Chimú". Squier.

arte del Viejo Mundo se realizan en un sentido inverso al acostumbrado. Por ejemplo, al explicar la pericia técnica empleada en la elaboración de tejidos chimú, Squier señala lo siguiente: "El tejido de algodón era notablemente fino y parejo, con veinticuatro hilos de trama y urdimbre por centímetro. Tengoun trozo de lo queseconsidera unespéci 


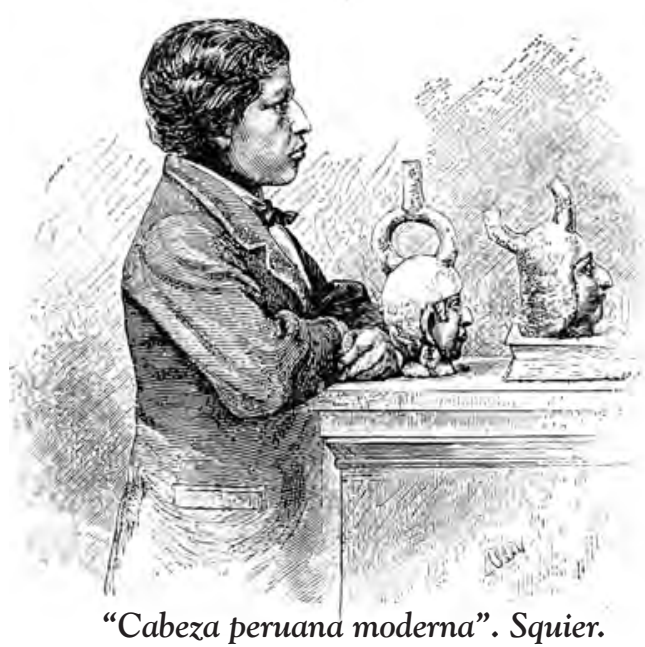

men muy fino de tela de momias egipcias, proveniente de las envolturas de un sacerdote desenrollado en eldepartamento egipcio de la Exposición Universal de París, que sólo tiene diecisiete hilos por centímetro" (1974:77-78).

La cerámica norteña le resulta valiosa por su gran variedad de formas y representaciones: seres humanos, costumbres e ideas, frutos, aves, peces, animales terrestres, formas geométricas, etc., que "encuentran ilustración y registro en estos restos sumamente frágiles y, a pesar de ello, casi imperecederos" (1974: 96-97).

Elogia la arquitectura inca comparándola con célebres obras europeas. Respecto a los muros de Ollantaytambo anota: "Es fácil confundirlos con la obra de Robert Guiscard y no son desemejantes a las fortificaciones medie-

\footnotetext{
"Vista de Pampa Maroni, con muro incaico, Cusco". Squier.
}

vales de ese jefe que cuelgan al borde de las colinas que existen sobre Salerno, en Italia" (1974:272). Elogia el ensamblaje preciso de los litos tallados que conforman los paramentos incas. En este sentido se atreve a afirmar la superioridad de los monumentos incas sobre construcciones contemporáneas en piedra: "El mundo no tiene nada que mostrar en materia de corte y encaje de piedras que sobrepase la precisión y habilidad desplegadas en las estructuras incaicas del Cuzco. Allí toda la obra moderna de esta clase y existen algunos ejemplos magnificos de habilidad parece tosca y bárbara en comparación" (1974:236). Además, percibe ese aire de "eternidad" que caracteriza a los muros incas: "iObras que, a no ser que sean perturbadas por violencias sistemáticas, durarán cuando el Capitolio de Washington haya caído en la decadencia y el neocelandés de Macauley contemple las ruinas de San Pablo desde los arcos desmoronados del Puente de Londres!" (1974 : 237).

Mención aparte merece su elogio del acllahuasi de Coatí, donde la obra humana y la naturaleza se conjugan para crear magníficas

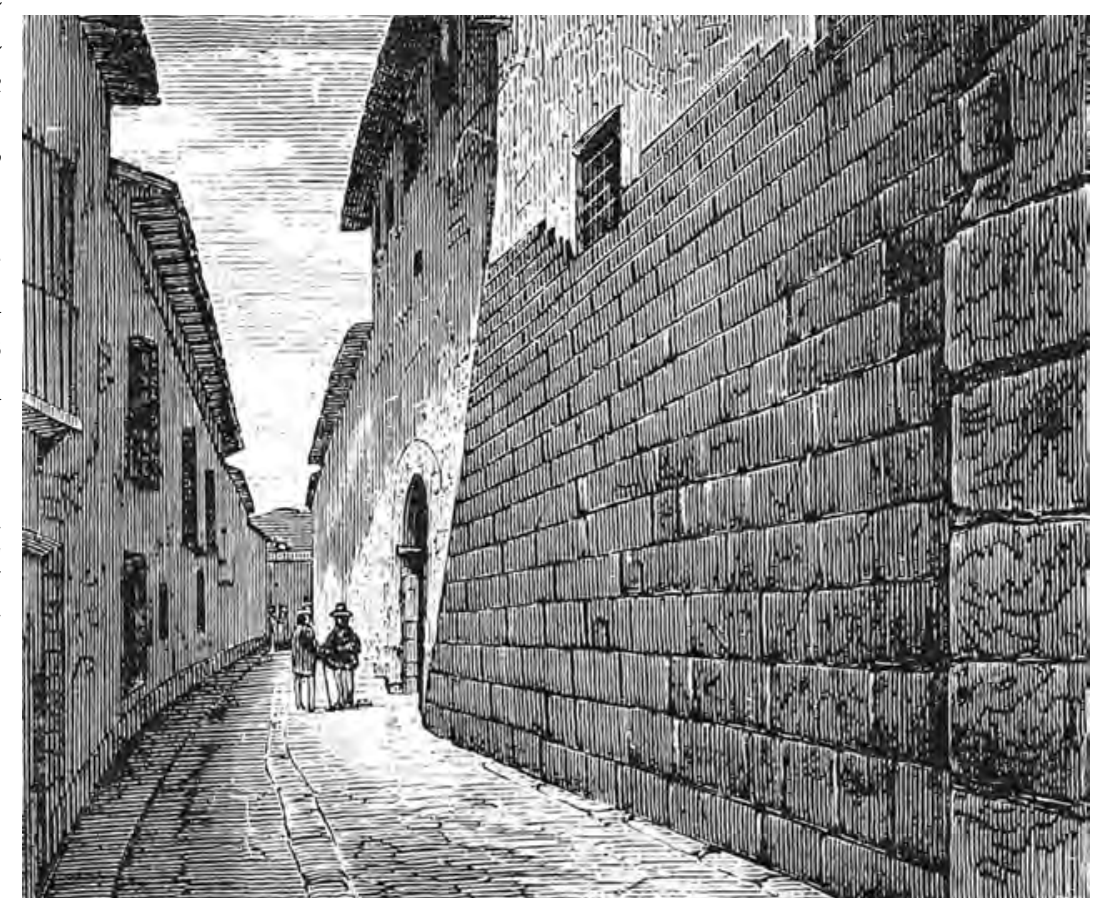


zbella aunque complicada serie de terrazas que descienden en armoniosas graduaciones desde el patio o explanada del convento hacia el lago. Semejante intento sería por igual confuso e insatisfactorio y sólo se debe decir en general que el gusto moderno difícilmente podría sugerir una disposición más agradable de plataformas o terrazas o el arte moderno llevar a cabo más satisfactoriamente las concepciones del proyectista" (1974 : 198).

Pero su audaz apertura a los logros de nuestras culturas, llega a la cima cuando compara el fino techo de paja del Sondorhuasi de Azángaro con un monumento romano: "Probablemente sobresaltaré a mis lectores clásicos y se me considerará presuntuoso si me atrevo a comparar el estilo y efecto de la cúpula de Azángaro con los de la cella del Templo de Venus, que está frente al Coliseo en la Ciudad Eterna" (1974 : 214).

El espíritu aventurero de Squier lo llevó a visitar sitios poco conocidos y de difícil acceso como por ejemplo la fortaleza de Quisque. El monumento se encuentra en un cerro del valle

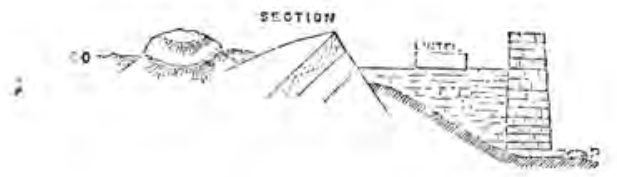

\section{.}

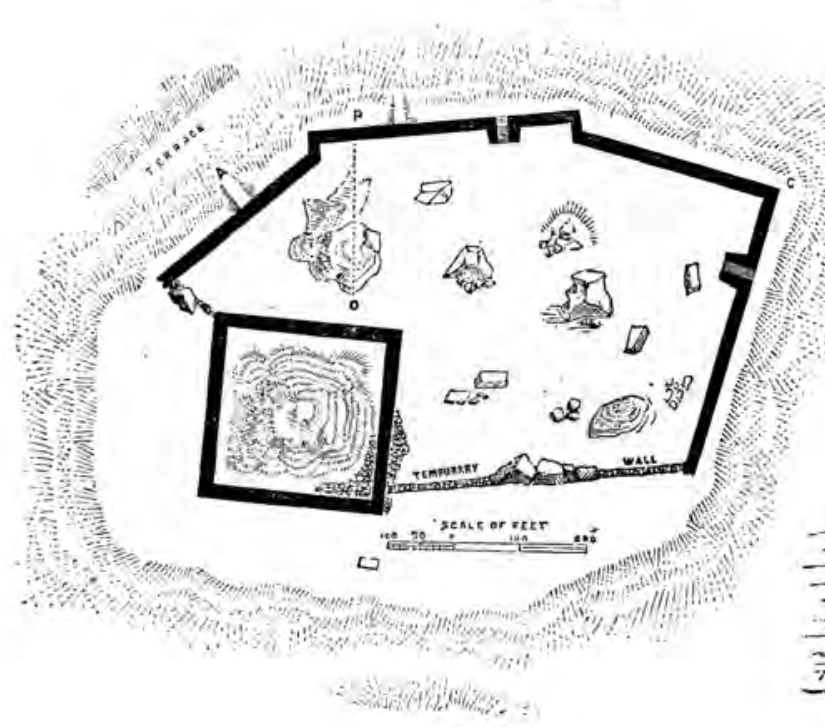

Quisque. Fotografía tomada de Samaniego (1992).

“El Sondor-Huasi”. Squier.
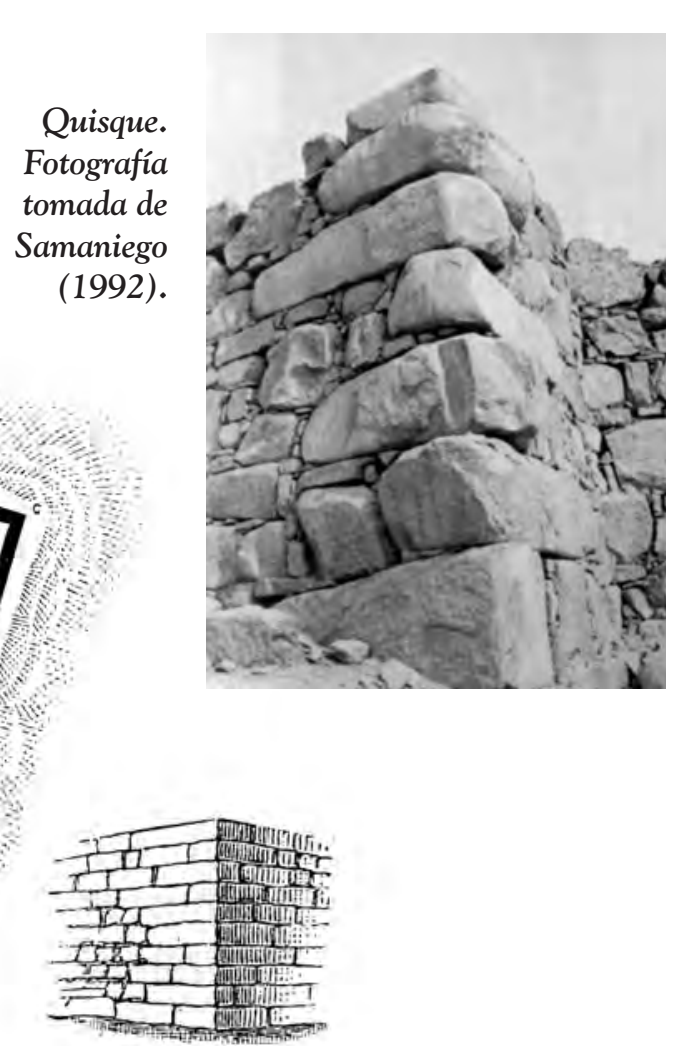

"Plano de la fortaleza de Quisque”. Squier. 
del río Nepeña y Lorenzo Samaniego lo relaciona con la cultura Virú (1992:32). Squier dejó un magnífico plano del sitio (1974 : 113).

El viajero vuelve a sorprendernos cuando explica su método de acercamiento a la cerámica norteña. Nos hemos permitido resumirlo de esta manera:

1. Las vasijas sagradas son "huacas" y contienen información sobre las ideas religiosas de los antiguos habitantes.

2. Son frecuentes las representaciones mitológicas.

3. Se rendía culto a las fuerzas de la naturaleza: de la tierra, del aire y del agua.

4. A falta de escritura se emplea el símbolo para expresar ideas.

5. Los dioses portan símbolos (animales u objetos) que indican su pertenencia a la tierra, el agua o el aire.

6. Las diversas divinidades se pueden identificar también por las coronas o tocados que ostentan.

7. Las representaciones mitológicas más comunes son aquellas que ilustran los combates entre dioses.

Como vemos, se trata de un auténtico proue

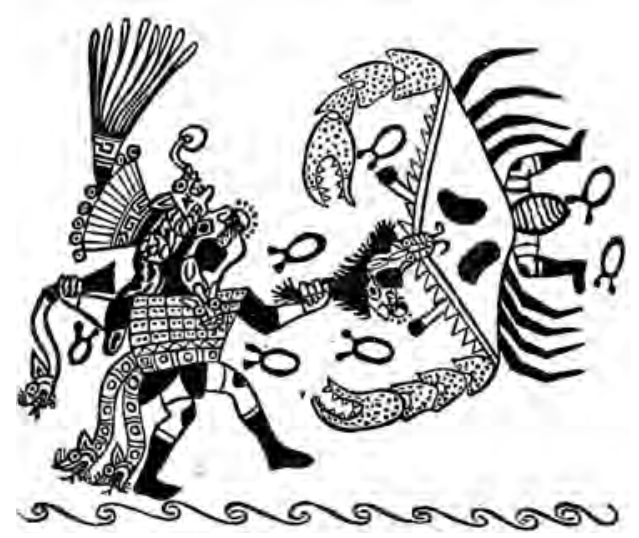

“Combate entre el Hombre de la tierra y el Hombre del mar". Squier. grama de estudio iconográfico planteado en el siglo XIX . También en esto Squier fue un precursor (1974:98-99).

Otro asunto notable es su descripción minuciosa de la Portada del Sol y la paradigmática imagen del Dios de los Báculos. ${ }^{4}$ El viajero norteamericano fotografió la portada y calcó sus diseños cuidadosamente. Sin embargo no se atreve a hacer interpretaciones. Sólo sugiere que la forma ondulada de los báculos puede ser una referencia al movimiento de las serpientes. Menciona la interpretación del francés D'Orbigny (el personaje central de la portada es un gobernante a quien vienen a rendir homenaje los pueblos sometidos), pero le llama "imaginativo filósofo" (1974 : 155-159).

III. Charles Wiener (1851-1913): Perú y Bolivia. Relato de viaje. Seguido de estudios arqueológicos y etnográficos y de notas sobre la escritura y los idiomas de laspoblaciones indígenas. ${ }^{5}$

La obra de este lingüista y filósofo austriaco se publicó en París en 1880, con la asombrosa cifra de 1100 grabados, 27 mapas y 18 planos. La viñeta de la página titular es un típico huaco retrato moche.

Wiener logró que el Servicio de Misiones del Ministerio de Instrucción Pública de Francia le encargara una expedición para realizar investigaciones de arqueología y etnografía en el Perú y Bolivia (1875-1877). Edgardo Rivera Martínez ha resaltado su "afiebrada pasión de verlo y abarcarlo todo" así como sus pretensiones de considerarse pionero de los estudios americanistas (1993: I, XI-XII).

Sobre la escultura tiene ideas muy firmes acerca de la inferioridad del arte andino: "Si su obra no alcanza la belleza de la obra griega ni la majestad de la egipcia, ni la vida de la india, dice lo que tiene que decir, ingenuamente es verdad, pero claramente. Ello era suficiente para el escultor autóctono y basta hoy al historiador" (1993: 616).

\footnotetext{
${ }^{4}$ Cristóbal Campana prefiere llamarlo Dios de los Cetros. Iconografía Chavín, conferencia dictada en el programa de los Miércoles Arqueológicos y Antropológicos del MAA-UNMSM (08/09/04).

${ }^{5}$ Hemos consultado la edición en español de 1993 (ver bibliografía).
} 


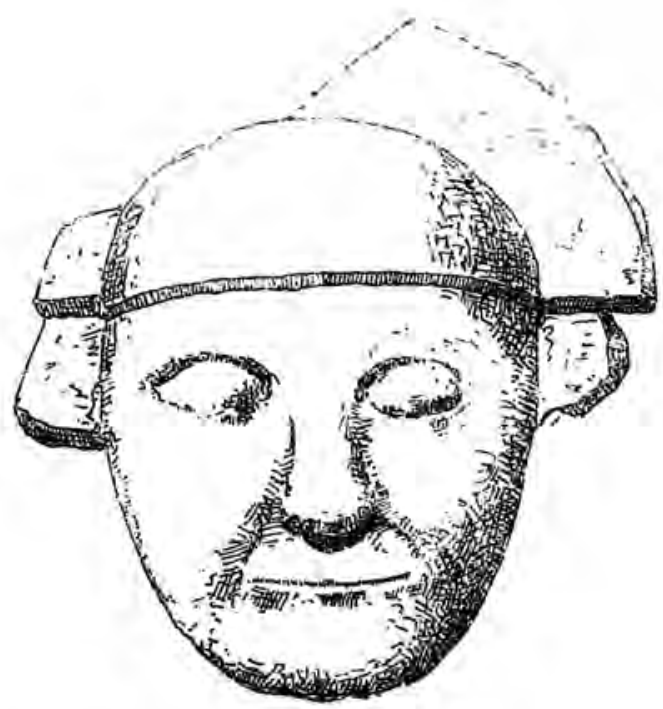

"Cabeza de hombre en alto relieve, granito gris; proveniente de Pashash". Wiener.

La referencia a la escultura griega es inevitable: "El arte de un pueblo no puede, por decir así, ser juzgado sino de acuerdo a la manera en que comprende e interpreta la belleza del cuerpo humano" (1993: 651). A la hora de comparar forzosamente las obras de sociedades tan diferentes, los productos del arte andino son reprendidos con severidad: la estatua griega expresa la "serenidad del genio majestuoso", el jarro peruano revela la "burlesca desvergüenza de un diletantismo rutinario" (1993 : 675). La explicación de esta diferencia la encuentra Wiener en el fenotipo andino: "Si el artista indígena reproduce en su obra estas características, contrarias a nuestras concepciones de lo bello, si no ha inventado lo que nunca ha visto sino imitado lo que impresionaba a sus ojos, tiene absolutamente el mismo mérito que el escultor clásico que produjo las obras maestras que estamos habituados a admirar" (1993:653). En otras palabras, el problema es el modelo: "... no es el artista, sino el modelo, la causa de lo que la crítica europea ha llamado hasta hoy, no sin razón, ausencia de gusto, de sentimiento, quizás incluso de valor. La fotografía de una peruana del pueblo, en la

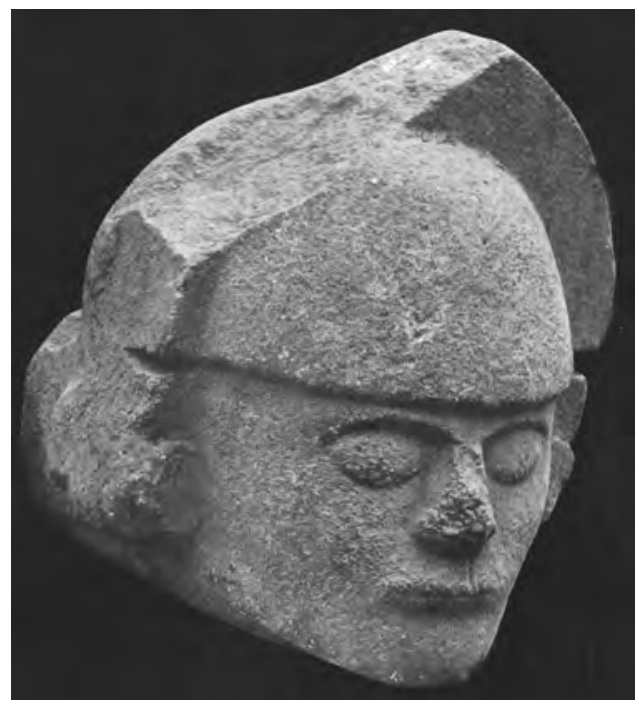

Cabeza clava del Callejón de Huaylas. MNAAHP. Fotografía de Casals, tomada de Larco, s/a.

actitud ordinaria de reposo, comparada a los vasos que ponemos a su lado, prueba que el artista ha representado fielmente lo que veía de continuo ante sí" (1993: 657). "Sigamos al peruano autóctono de hoy día durante algunos instantes, y comprenderemos por qué el artista del imperio del Tahuantinsuyo no concibió jamás ni un Apolo ni una Venus... la ley de la armonía de las formas, incluso de las dimensiones, no existe en estas criaturas" (1993 : 652).

No debe sorprendernos este horizonte limitado del intelectual del siglo XIX. También en 1880 se publicó un clásico de la historia mesoamericana: Historia antigua y de la conquista de México, de Manuel Orozco y Berra. La escultura indígena es evaluada con los mismos criterios de Wiener: "El estatuario no tenía elementos para llegar a la perfección: faltábale el estudio de las ropas en trajes vistosos y galanes, y sus creencias religiosas no les permitían ejercitarse en el cuerpo desnudo, pues los dioses no se complacían en mostrar sus bellezas plásticas" (Fernández, 1972:42). ${ }^{6}$ Tanto en Wiener como en Orozco se escucha el eco de Lessing: "Pues si hoy día la pintura es cultivada en general, en un sentido muy amplio, como el arte que representa los cuerpos

${ }^{6}$ Alfonso Castrillón ha señalado los criterios para apreciar la escultura lítica de la América Antigua. Afirma que los 
en superficies planas, la sabiduría de los griegos en cambio le había asignado límites mucho más estrechos, circunscribiéndola únicamente a la representación de los cuerpos dotados de belleza. El artista griego no representaba más que lo bello, y aun la belleza vulgar, la belleza de orden inferior, no era para él sino un motivo accidental, que no ejecutaba más que como ejercicioopasatiempo. Loque en suobra debía encantarera laperfección delobjetomismo..."(1946:19).

Wiener era rotundo en su apreciación: el artista andino fracasó en la representación del cuerpo, pero tuvo éxito modelando retratos: "He ahi por qué las bellas manifestaciones de la cerámica peruana son aquellas en que se ha suprimido por completo el cuerpo humano, y en las que el artista se ha limitado a representar la cabeza... hallamos piezas verdaderamente asombrosas como reproducción, como retrato del rostro del indígena. La expresión indiferente, grave o triste, habitual en este pueblo, sus accesos de alegría violenta, están inmortalizados por el modelador (sic) incomparable de algunas de estas obras, las mismas que, fuera de su interés etnográfico o arqueológico, ofrecen un valor artístico indiscutible"(1993:659-662).

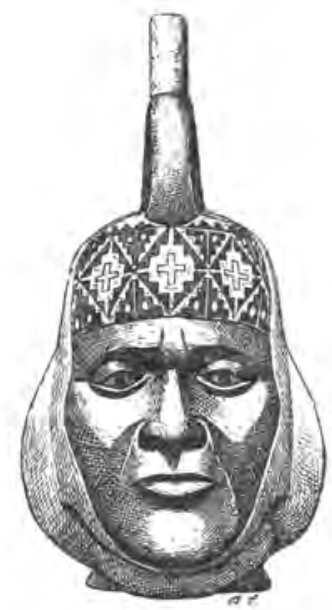

Huaco retrato. "Hallado en Trujillo".Wiener.
En ese sentido, criticó con agudeza a aquellos que cuestionaban la trascendencia de los huaco retratos porque eran objetos utilitarios -hoy sabemos que más bien eran rituales-, afirmando un valor que ahora resulta incuestionable: "Consideramos injusto decir que el destino del objeto rebaja su valor, y que es indigno que tal rostro, a menudo majestuoso, no sirva más que de máscara a un vaso de chicha, y que a su frente, a la bandeleta que la rodea, se adhieran los labios del borracho. Hay allí una falsa interpretación: una costumbre nacional no tiene nada que pueda mancillar a una obra artística" (1993: 663).

No ignoró a las botellas silbadoras: “... si el indio se preocupó rara vez por la elegancia de la línea, por la pureza de la forma, se preocupó siempre, en cambio, por la vida y el movimiento en la naturaleza... por eso se esforzó con notable ingenio en dar la palabra a los seres de arcilla que modelaba. Enseñó a su mono y a su loro a gritar, a su hombre que bebe a lanzar gritos de satisfacción" (1993: 668669). Y agrega: "En una nación llegada a la cumbre de la civilización, se trataría de recursos para divertir a los niños; en una nación que despierta, son pruebas de una observación inteligente de la naturaleza tomadas de lo vivo" (1993 : 669).

La famosa paccha de Sayhuite (Apurímac) llamó la atención del viajero; la complejidad simbólica de la escultura lo llevó a ensayar una interpretación que reproducimos a continuación: "... Un bloque de granito gris recubierto casi por entero de esculturas en alto-relieve, la fuente de Quonncacha. Cuando se examina con atención el conjunto, a primera vista caótico, se descubren animales de toda clase en medio de estanques, de torrentes, de casas y de muros de sustentación. Uno se siente tentado a creer que se trata de una obra simbólica, objeto de un culto místico; se podría incluso pensar, por un razonamiento inverso, que se está frente a la obra sin objetivo preciso de un escultor extravagante...

criterios occidentales de apreciación artística - por ejemplo la "belleza"- no sirven para entender el "sistema artístico americano". Para el caso concreto de Chavín, Castrillón defiende las categorías de lo "terrible" y lo "sublime". Ver : "Para una apreciación del arte lítico en América". Introd. A la exposición Piedra milenaria . Galería del Banco Continental, febrero de 1978. Reproducido en: iElojodelanavajaoelfilodela tormenta? Lima, Universidad Ricardo Palma, 2001.pp.90-91. 


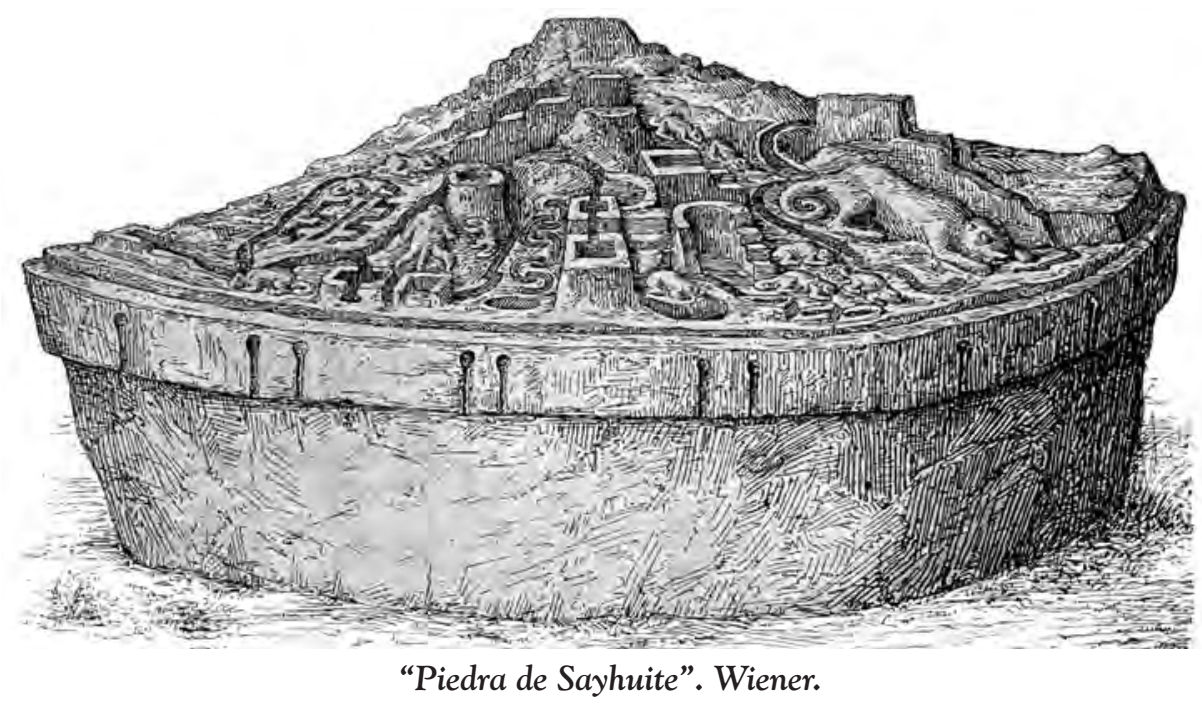

Un examen detenido de esta escultura probará, por otra parte, que pertenece a la categoría de trabajos de observación, que se trata de una imitación de la naturaleza: el bloque representa un terreno accidentado, una montaña de la cordillera. Cuando se divisa a lo lejos las siluetas de las cumbres de las montañas, las rocas de líneas extrañas ofrecen, por ilusión óptica, formas más o menos exactas de seres animados.

He ahí por qué en toda región accidentada es posible encontrar las montañas 'del León, de la Serpiente, de la Virgen', etc. El autor de la fuente acentuó y tradujo ese fenómeno, pero en lugar de pseudo-leones o simili-serpientes, figuró los accidentes del terreno por medio de leones, serpientes, batracios y toda la fauna especial de la cordillera...

La constitución física de la cordillera ha sido traducida por un artista observador, que supo introducir allí la obra humana: los meandros regulares de los canales de irrigación, los diques que desvían las aguas de un torrente para fertilizar los campos, los llanos cultivados, los estanques de retención, los de evacuación, etc... He ahí una reproducción fiel de la región de los Andes y de la obra de arquitectos e ingenieros peruanos. Se trata, de algún modo, de una sintesis topográfica, que prueba con qué lógica manera los antiguos habitantes de la región comprendían el mundo físico, del que tan admirablemente sabían sacar provecho" (1993 : 304-306).

La paccha de Sayhuite causó interés en Europa y fue presentada -replicada en cementoen la exposición universal de París de 1878. Incluso reprodujeron su circulación hidráulica (Riviale, 2000: 323).

Otro aspecto que nos interesa destacar es su análisis de la iconografía representada en la Portada del Sol. Wiener considera que se trata del Dios Sol, de cuya cabeza brotan rayos, unos culminan en cabezas de "león" y otros son "figuraciones de la potencia viril". Este personaje que simboliza la fuerza y la reproducción, se relaciona con el símbolo de la fecundidad que aparece en el pedestal inferior: se trata de la luna, que es representada por la figura de un pez arqueado. El explorador observa con sagacidad que el número tres y sus múltiplos predominan en toda la composición (1993 : 747-749). ${ }^{7}$

De todas las artes andinas, la que mejor efecto causó en el viajero austriaco fue la arquitectura. Su elogio del cromatismo de los muros cos-

\footnotetext{
${ }^{7}$ Hoy sabemos que esta imagen estaba bastante difundida; además de la Portada del Sol, se le encuentra en una estatuilla Pukara (Museo Nacional de Arqueología, Antropología e Historia), las tinajas ceremoniales Wari descubiertas en Pacheco (Ica), un kero de madera hallado en Chen Chen (Moquegua), etc.
} 
ños es notable: "Según la finalidad de la construcción los muros eran rojos o amarillos, o incluso estaban cubiertos por un damero de ambos colores; a veces también se destacaban, sobre un fondo rojo, dibujos amarillos, y a la inversa. Ahi también la ausencia de ventanas permitió el despliegue ancho e ininterrumpido del motivo, cuyo colorido, en la luz dorada del clima ecuatorial no produce de ningún modo el efecto chillón que una gama de colores semejantes ocasionaría en nuestras grises regiones... Al contrario, esos tonos se conciertan perfectamente con el suelo amarillo, con la vegetación de un verde uniforme, con el cielo de un solo tono, por así decir sin matices, de manera que el todo causa la impresión de un rico conjunto de colores francos, agradables a los ojos como un tapiz de oriente que exhibe sus tonos cálidos a la luz resplandeciente del suelo nativo"(1993 : 526-527).

Las líneas horizontales que predominan en la arquitectura inca, la ausencia de columnas, estatuas y otros "accidentes", permitieron a algunos críticos censurar nuestros edificios por su falta de "riqueza" y "carácter". Ante este reparo de la arquitectura monumental moderna, Wiener ofrece una inteligente réplica que es realmente de antología: "Mas ino hay una finalidad artística, inconsciente quizás pero indudable y de gran efecto, en esta extrema simplicidad? El arte indígena de esta época traduce de manera sorprendente el carácter de una nación que se sintió lo suficientemente vigorosa como para oponer su fuerza personal a la potencia majestuosa de la estructura de los Andes, con un gusto lo bastante seguro, un juicio lo bastante firme, una voluntad lo bastante orgullosa, como para corregir, si puedo expresarme así, las irregularidades del mundo físico. La gran línea horizontal de los remates de estos monumentos forma un contraste sorprendente con las cresta volcánicas de los Andes... Elautóctono opuso la superficie uniforme y sin relieve de sus templos a las arrugas profundas que surcan las vertientes abruptas de las cadenas de montañas, cuya solidez a menudo socavan" (1993: 584).

Sus observaciones sobre los indígenas contemporáneos son bastante duras. Por ejemplo basta citar su apreciación sobre los morochucos: "Se diría que los descendientes de los antiguos han querido demostrar la medida en que puede degenerar una raza y perder la tradición de las artes y los oficios, el amor al trabajo y el hábito del orden.

Involuntariamente uno se traslada a la época en que los indígenas levantaron los grandes monumentos de Vilcashuamán y ve entonces que de sus nuevos amos, los españoles, no aprendieron sino el arte de la destrucción" (1993 : 284-285).

Marcoy, Squier, Wiener. Éstas fueron las opiniones de tres viajeros decimonónicos, acertados unas veces, equivocados otras, apasionados siempre. Tres hitos en el descubrimiento de ese arte que hoy nos sigue deslumbrando, complaciendo y perturbando.

Los diseños Tiwanaku aparecieron registrados en muchos textos liminares de la arqueología peruana. Por ejemplo, en el frontispicio de Antigüedades Peruanas (1851). En este caso, la Portada del Sol sirve de soporte a los retratos de los catorce incas.

En el Diccionario de arte y arqueología de Mollet (Londres, 1883), la portada monolítica boliviana es atribuida a la cultura inca y se le llama "templo peruano". En la ilustración 379 aparece el famoso relieve como "fachada" del Intihuasi o casa del Sol (Mollet,1998: 210). Sin embargo, en la ilustración 71 se aprecia el mismo relieve en una versión simplificada: del Dios de los Cetros sólo se aprecia su cabeza con rayos reposando directamente sobre el pedestal. El cuerpo ha sido ignorado totalmente (Mollet, 1998:57).

Esta compleja imagen, tan densa en sus posibilidades semánticas, aparece coronando tres obras arquitectónicas paradigmáticas de la década del 20: el Museo de la Cultura Peruana (en ese tiempo Museo de Arqueología Peruana, colección Víctor Larco Herrera), la Escuela de Bellas Artes y el Pabellón del Perú para la exposición de Sevilla. El primero, en estilo "neoinca", fue diseñado por Ricardo Malachowski ; los otros dos fueron obra de Manuel Piqueras, creador del estilo "neoperuano". En las tres fachadas se luce la poderosa imagen solar del Dios de los Cetros de Tiwanaku . Resulta interesante la atracción de este símbolo altoperuano. Era necesario utilizar un ícono solar que representara con contundencia al Antiguo Perú y para esa época no se conocía mejor imagen que ésta. Nótese que hasta la greca que rodea su rostro ha sido tomada para el logotipo de la popular bebida INKA KOLA. La riqueza simbólica de esta imagen no pasó desapercibida para Squier y Wiener en sus libros precursores. 


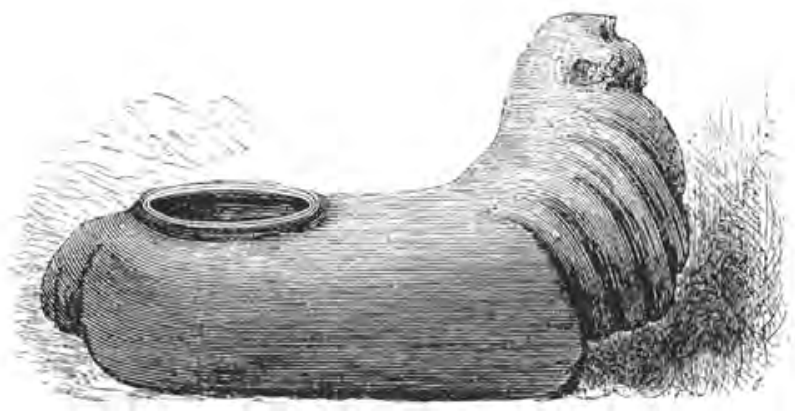

Conopa representando un camélido. Marcoy la describe como "Vaso de remedio en traquita profiroide".

Ceramio zoomorfo. "Hallado en Recuay". Wiener.
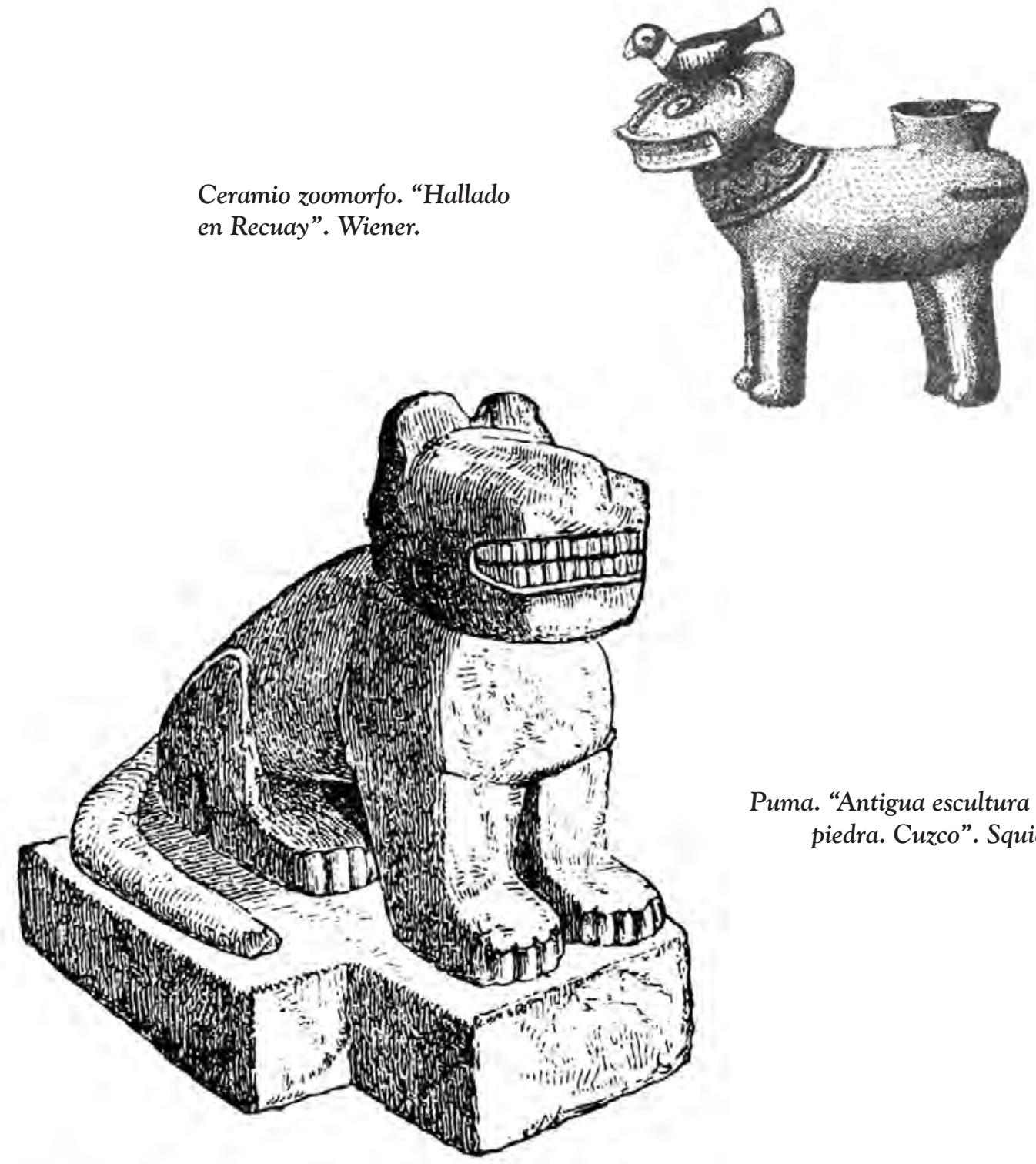

Puma. "Antigua escultura de piedra. Cuzco". Squier. 


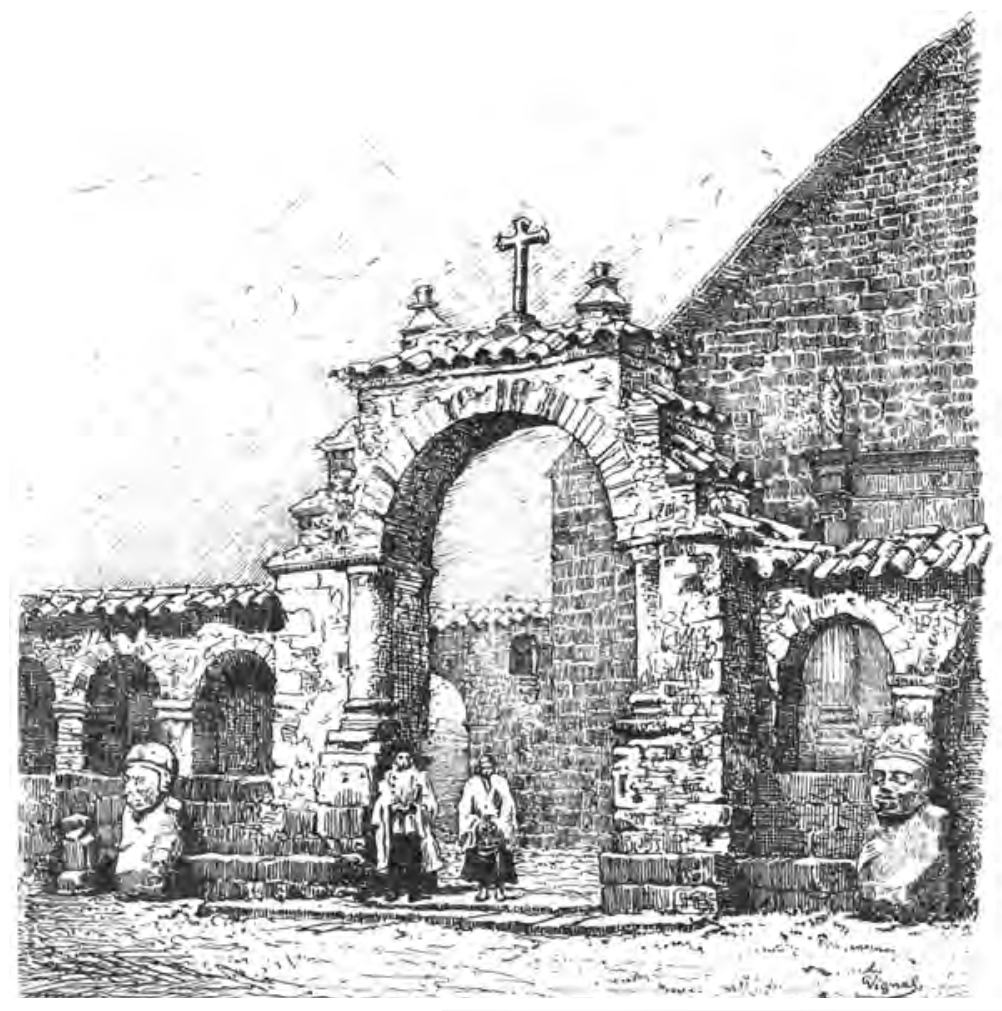

"Entrada de la iglesia de Tiahuanaco". Wiener.

La misma portada en una fotografía publicada por Uhle y Stübel: Las ruinas de Tiahuanaco en el altiplano del Perú

Antiguo, 1892. Fotografía tomada de: Kaulicke (1998).

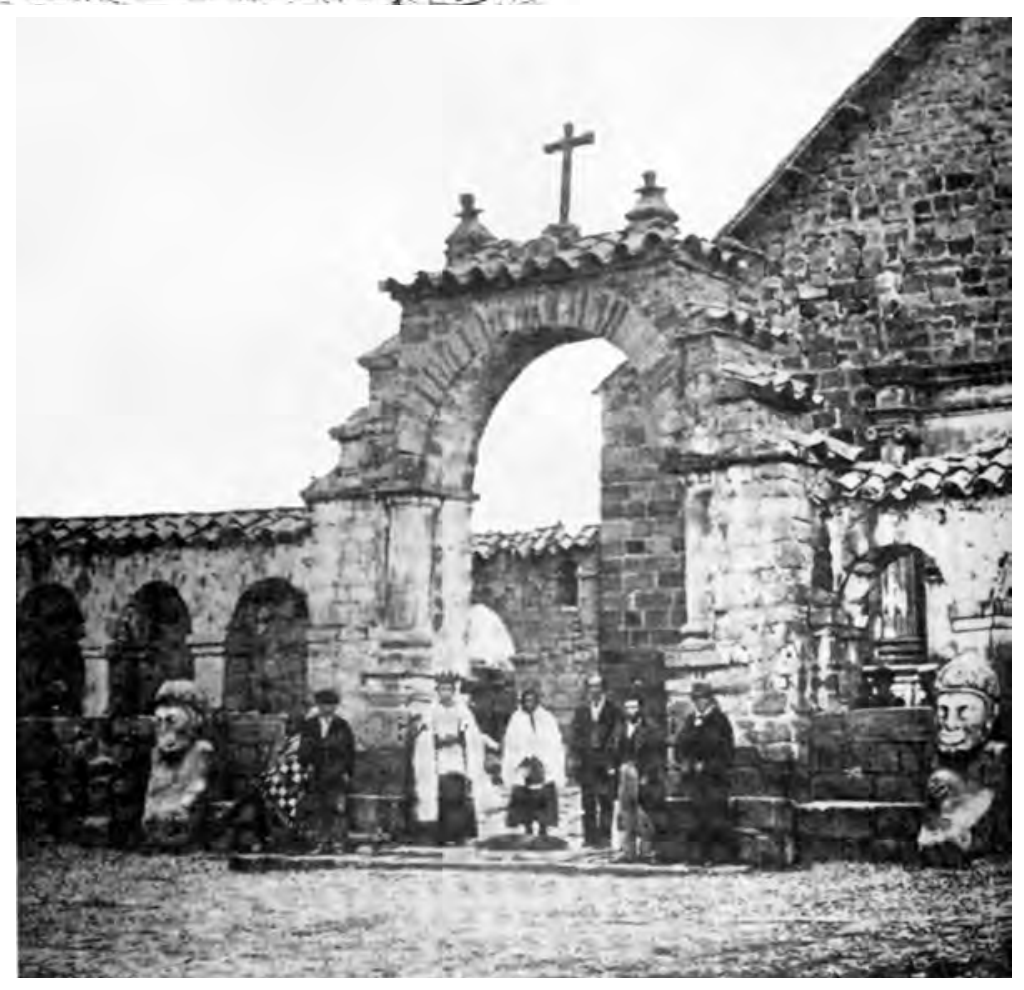




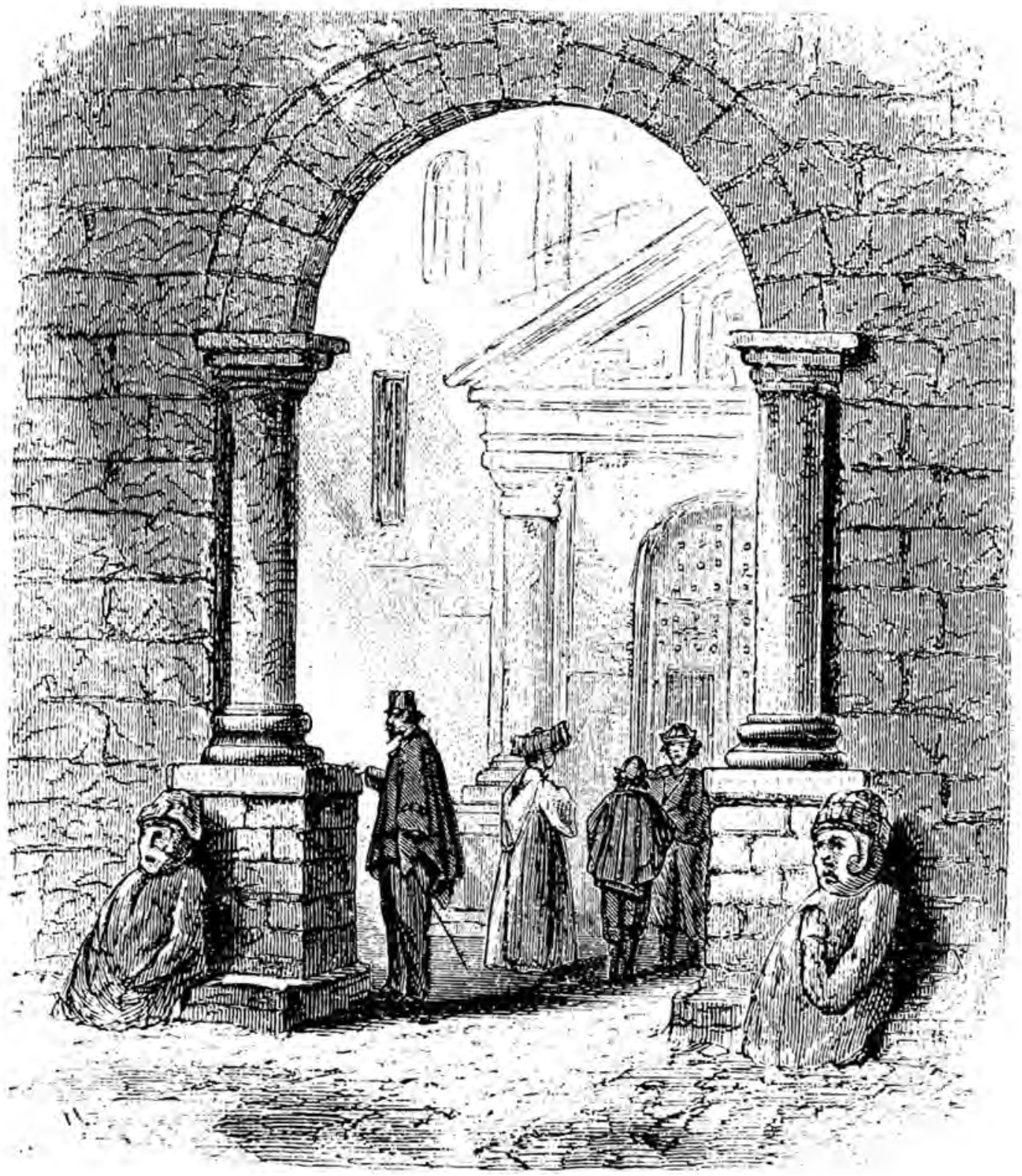

“Columnas y figuras de piedra en Tiahuanaco". Squier. 


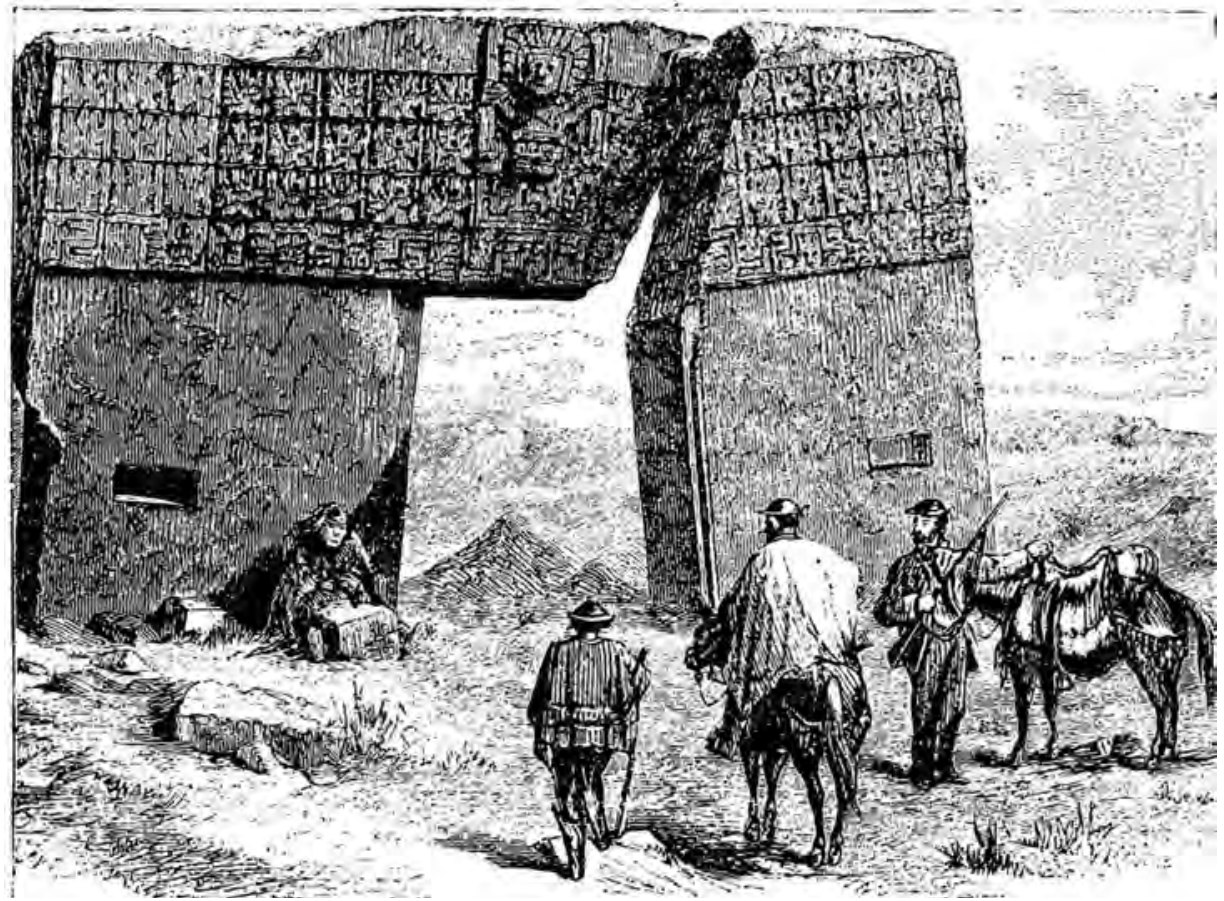

Portada del sol. Squier.

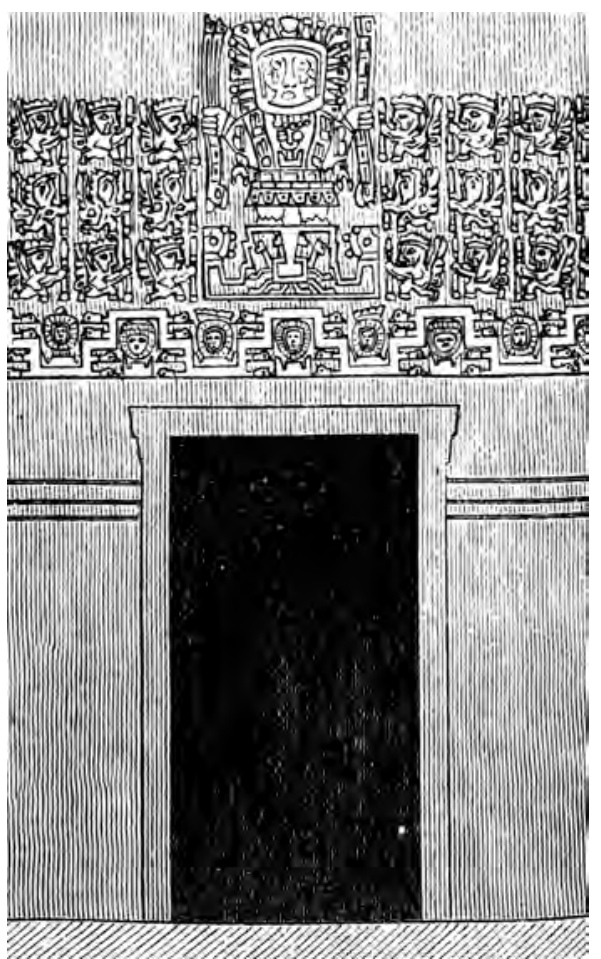

Portada del sol según Mollet (1883).

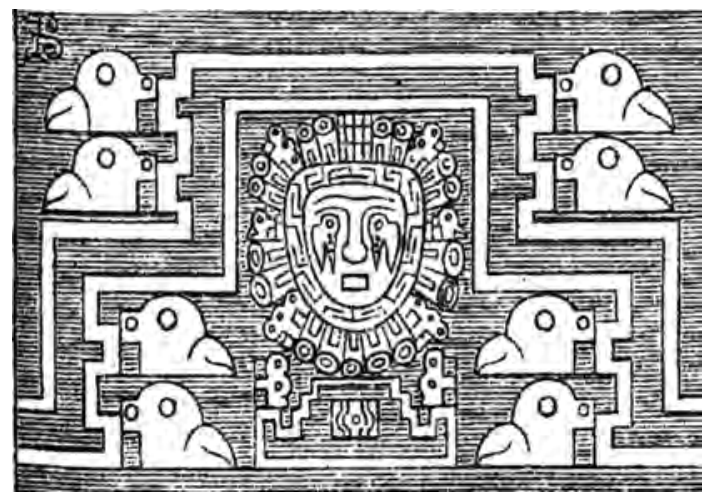

Divinidad de la Portada del sol según Mollet (1883).

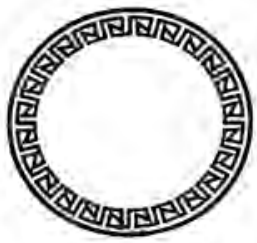

Greca de inspiración Tiwanaku en el logotipo de bebida gaseosa. 


\section{Bibliografía}

Carlson, Uwe

2000 "Reiss y Stübel en Ancón”. En: Museo de Arte de Lima. El inicio de la arqueología científica en el Perú: Reiss y Stübel en Ancón. Exposición de litografías. 27 de abril - 14 de mayo de 2000.

Castrillón, Alfonso

2001 ¿El ojo de la navaja o el filo de la tormenta? . Lima,Universidad Ricardo Palma.

Chaumiel, J.P.

2001 "Un viajero sin prisa a mediados del siglo XIX”. En: Marcoy, Paul. Viaje a través de América del Sur. Del océano Pacífico al océano Atlántico. Lima: Instituto Francés de Estudios Andinos / PUCP / BCRP / Centro Amazónico de Antropología Aplicada.

Fernández, Justino

1972 "Coatlicue. Estética del arte indígena antiguo", (1ra.ed. 1954). En: Estética del arte mexicano. México: Instituto de Investigaciones Estéticas de la UNAM.

Kaulicke, Peter (ed.)

1998 Max Uhle y el Perú Antiguo. Lima: PUCP.

Kauffmann, Federico

2002 Historia y arte del Perú Antiguo. Tomo 3. Lima: Peisa / La República / Gloria.

Larco Hoyle, Rafael

s/f Escultura lítica del Perú pre-colombino. Lima: Instituto de Arte Contemporáneo. Fotografías de José Casals.

Lessing, Gotthold Ephraim

1946 Laocoonte (1766). Buenos Aires: Argos.
Marcoy, Paul

2001 Viaje a través de América del Sur. Del océano Pacífico al océano Atlántico. 2 t. Trad. Edgardo Rivera Martínez. Pról. J.P. Chaumiel. Lima: Instituto Francés de Estudios Andinos / PUCP / BCRP/Centro Amazónico de Antropología Aplicada.

Mollett, J. W.

1998 Diccionario de arte y arqueología (1883). Madrid: Edimat Libros.

Ravines, Rogger

1999 "Johann Jakob Von Tschudi peruanista y anticuario". Boletín de Lima, vol. xxI, n 117, pp. 33-52.

Riviale, Pascal

2000 Los viajeros franceses en busca del Perú Antiguo (1821-1914). Trad. Edgardo Rivera Martínez. Lima: PUCP / Instituto Francés de Estudios Andinos.

Samaniego, Lorenzo

1992 Moro: Historia y turismo. Lima: Municipalidad Distrital de Moro / Gobierno Regional Chavín.

Squier, Efraim George

1973 Un viaje por tierras incaicas. Crónica de una expedición arqueológica (1863-1865). Pról. Raúl Porras. La Paz: Los Amigos del Libro .

Wiener, Charles

1993 Perú y Bolivia. Relato de viaje. Trad. y pról. de Edgardo Rivera Martínez. Lima: Instituto Francés de Estudios Andinos / UNMSM/CONCYTEC. 